\title{
Unilateral peters anomaly in a nigerian child: a case report
}

\begin{abstract}
Ten-week-old female infant presented in our clinic in March, 2013 with history of small right globe since birth. There is associated history of whitish speck in the affected eye. The child is a product of term pregnancy which was uneventful. Mother denied any history of febrile illness during pregnancy. Nil history of maternal rashes, nil hearing or visual challenges, nil use of any drug apart from routine ante-natal haematinics. No history of use of traditional medicine in the course of her pregnancy. The patient is the second child of her parents. There is no similar occurrence in the other sibling or in any other member of the monogamous family. Ocular examination revealed right microphthalmos, microcornea and cornea opacity with pannus. The whole extent of the cornea was affected. An assessment of Right Eye Peters Anomaly was made. The ocular ultrasound done revealed that the right globe measured $16.1 \mathrm{~mm}$ in its AP diameter and the left globe measured $16.9 \mathrm{~mm}$. There was cataract in the right eye and the anterior chamber was absent with adherence of the iris to the cornea. Patient was to be placed on cosmetic contact lens in future when she would be old enough to manage it.
\end{abstract}

Keywords: cornea opacity, microphthalmos, unilateral, nigerian, child
Volume 7 Issue 4 - 2017

\author{
Omolase Charles Oluwole,' Egberongbe \\ $\mathrm{AA},{ }^{2}$ Sotiloye OA,' Adeosun OA,' Omolase \\ $\mathrm{BO}^{2}$ \\ 'Department of Ophthalmology, Federal Medical Centre, \\ Nigeria \\ ${ }^{2}$ Department of Radiology, Federal Medical Centre, Nigeria
}

Correspondence: Omolase Charles Oluwole, Department of Ophthalmology, Owo, Ondo State, Nigeria,

Emailomolash2000@yahoo.com

Received: August 29, 2017 | Published: September 19, 2017

\section{Introduction}

Peter's anomaly is a form of congenital corneal opacity. It is associated with malformation of the anterior segment of the eye. ${ }^{1}$ The aetiology of the condition is not clear. The most likely causes include genetic, infectious, traumatic and toxic factors. ${ }^{1}$ Peter's anomaly is a rare form of anterior segment dysgenesis in which abnormal cleavage of the anterior chamber occurs. The condition may involve the central or entire cornea. The leucoma is associated with iridocorneal adherences at the area of the leucoma. In the inherited form, mutations involve the PAX6 gene. ${ }^{2}$ Peters' anomaly was described by Peters about one hundred years ago. ${ }^{3}$ It is a rare condition worldwide, however the incidence rate is unknown. The condition does not have racial or sexual predilection. A study done by Bhandari et al., ${ }^{4}$ Showed equal distribution in both sexes. There are two types of Peters anomaly based on the state of the lens namely type 1 and type 2 . In type 1 , the lens may or may not be cataractous but the lens does not adhere to the cornea. In type 2, the lens is cataractous and adheres to the cornea. Type 1 is usually unilateral while type 2 is bilateral in $60 \%$ of cases. The cornea is usually clear at the periphery and vascularisation is not common however there may be sclerization of the limbus.

\section{Case history}

A 10-week-old female infant presented in our clinic in March, 2013 with history of small right globe since birth. The mother noticed patient to have small right globe since few hours after birth. There is associated history of whitish speck in the affected eye. The child is a product of term pregnancy, which was uneventful. Mother denied any history of febrile illness during pregnancy. Nil history of maternal rashes, nil hearing or visual challenges, nil use of any drugs apart from routine ante-natal haematinics, nil ingestion of native concoction during pregnancy. Mother received routine antenatal Tetanus Toxoid vaccination. She neither smoked cigarette nor drank alcohol and did not chew kola either. Child was delivered by spontaneous vagina delivery, vertex presentation. She cried spontaneously immediately after birth and the umbilical cord were cut using sterile cord scissors. She had received immunization according to National Programme on Immunization schedule. She had also been achieving all the normal developmental milestones. There is no history of any febrile illness since birth. She is the second child of her parents. There is no similar occurrence in the other sibling or in the family.

Ocular examination revealed right microphthalmos, micro cornea and cornea opacity with pannus. General and systemic examination did not reveal any other abnormality. An assessment of right Peter's anomaly was made. The nature of this condition was explained to patient's parents with counselling on how to raise the patient. Consent was obtained from the mother and clinical photograph of the condition was taken. The ocular ultrasonography done revealed that the right globe measured $16.1 \mathrm{~mm}$ in its AP diameter and the left globe measured $16.9 \mathrm{~mm}$. There was cataract in the right eye and the anterior chamber was absent. The left eye was sonographically normal. It is our belief that patient may benefit from the use of cosmetic contact lens in future (Figure 1).

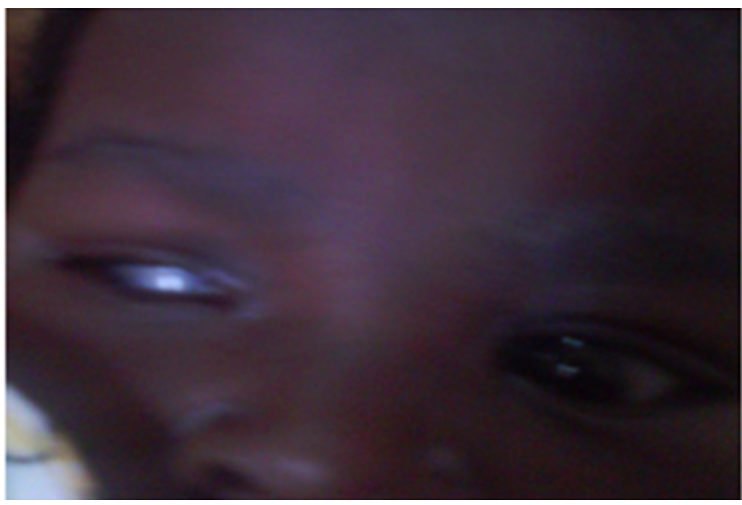

Figure I Child with right eye peters anomaly. 


\section{Discussion}

The early presentation of the patient is quite commendable. This may be related to the rarity of the ocular condition and the fact that the parents were enlightened. Most cases of Peter's anomaly are sporadic however the inherited ones could be of autosomal recessive and dominant modes of inheritance. It is associated with abnormalities of chromosome $4 .{ }^{6}$ We could not establish family history of similar presentation in the family of this patient. The other child of the parents was also said to be normal and in stable condition. Based on this fact, it is our considered opinion that the case may actually be a sporadic one. Peter's anomaly is often an isolated ocular defect but there may be associated ocular and systemic anomalies. However further examination of the patient did not reveal any other systemic abnormality. This may be related to the fact that the condition was unilateral as bilateral Peter's anomaly is more often associated with systemic anomalies. The globe was observed to be small and this was confirmed with the aid of ultrasonography. The associated anterior segment anomalies with Peter's anomaly include glaucoma, anterior polar cataract, cornea plana, sclerocornea, microphthalmos, colobomata as well as mesodermal dysgenesis of the anterior chamber angle and iris. ${ }^{7}$ Peters anomaly may be associated with systemic anomalies like limb deformities, craniofacial anomalies, cleft lip and palate as well as genitourinary defects. ${ }^{8-10}$

Treatment of Peter's anomaly is challenging and unsatisfactory. The outcome of corneal transplantation is not rewarding due to post operative complications like graft failure, cataract, retinal detachment and glaucoma. ${ }^{11}$ Alternative treatment measures include rotation of corneal autograft, atropinisation of the pupil most especially if the visual axis is spared and optical iridectomy. The involvement of the whole extent of the cornea and the microphthalmic globe are associated with poor prognosis for visual recovery. Affectation of only one eye is also risk factor for amblyopia. The patient was not suitable for corneal grafting in view of the vascularisation of the cornea. Optical iridectomy or atropinisation was also not considered as the whole extent of the cornea was affected. In view of the poor prognosis coupled with the cosmetic challenge, the patient was to be placed on cosmetic contact lens when she is old enough to manage contact lens.

\section{Conclusion}

We conclude that prompt presentation and treatment of patients with Peter's anomaly is desirable. There is need to create more awareness about the condition among health care providers and the populace in view of the fact that it is rare. Multidisciplinary approach should be adopted in the management of affected patients most especially those with associated systemic anomalies.

\section{Acknowledgments}

None.

\section{Conflicts of interest}

There are no conflicts of interest.

\section{Funding}

None.

\section{References}

1. Meyer I, Rolin H, Medeiros A, et al. Peters' Anomaly, Clinical and Therapeutic Aspects: Case Report. Arq Bras Oftalmol. 2010;73(4):367369.

2. Trabaccli G, Piantanida A, Bandello F, et al. Congenital Aphakia in Peters' Anomaly Syndrome: A Case Report. Acta Ophthalmol Scand. 1997;75(5):595-597.

3. Peters A. Ueber angeborne Defektbildung der Descemetschen Membran. Klin Mbl Augenheilk. 1906;44:105-119.

4. Bhandari R, Ferri S, Whittaker B, et al. Peters Anomaly: Review of the Literature. Cornea. 2011;30(8):939-944.

5. Ozeki H, Shirai S, Nozaki M, et al. Ocular and Systemic Features of Peters Anomaly. Graefes Arch Clin Exp Ophthalmol. 2000;238(10):833-839.

6. Hittner HM, Ferrel RE, Antoszyk JH, et al. Autosomal Dominant Anterior Dysgenesis with variable expressivity-probable linkage to MNS blood group on chromosome 4. Pediatr Res. 1981;15:56.

7. Kenyon KR. Mesenchymal Dysgenesis in Peters' Anomaly, Sclerocornea and Congenital Endothelial Dystrophy. Ex Eye Res. 21(2):125-142.

8. Bhat YR, Sanoj KM. Sclerocornea. Indian Pediatr. 2005;42:277.

9. Rezende RA, Uchoa UB, Uchoa R, et al. Congenital Cornea Opacities in a cornea referral practice. Cornea. 2004;23(6):565-570.

10. Kivlin JD, Fineman RM, Crandall AS, et al. Peters' Anomaly as a cause of genetic and non genetic syndromes. Arch Ophthalmol. 1986;104:61-64.

11. Gollamudi SR, Traboulsi EI, Chamon W, et al. Visual Outcome after Surgery for Peters Anomaly. Ophthalmic Genet. 1994;15(1):31-35. 